\title{
The novel pyrazolin-5-one bearing thiazolidin-4-ones: synthesis, characterization and biological evaluation
}

\author{
S. M. Holota ${ }^{1,2,3}$, I. O. Nektegayev ${ }^{1}$, I. I. Soronovych ${ }^{3}$, I. I. Chubuchna ${ }^{1}$, \\ M. A. Kolishetska ${ }^{1}$, S. P. Sysak ${ }^{1}$, M. S. Regeda ${ }^{1}$, R. B. Lesyk ${ }^{1,4}$ \\ ${ }^{1}$ Danylo Halytsky Lviv National Medical University \\ 69, Pekarska Str., Lviv, Ukraine, 79010 \\ ${ }^{2}$ Lesya Ukrainka Volyn National University \\ 13, Voli Ave., Lutsk, Ukraine, 43025 \\ ${ }^{3}$ Lviv Medical Institute \\ 76, V. Polischuk Str., Lviv, Ukraine, 79018 \\ ${ }^{4}$ University of Information Technology and Management in Rzeszow \\ 2, Sucharskiego Str., Rzeszow, Poland, 35-225 \\ golota_serg@yahoo.com,roman.lesyk@gmail.com
}

\begin{abstract}
Aim. Synthesis, structure determination, in vivo study of anti-inflammatory (anti-exudative) and ulcerogenic activity, estimation of an impact of novel pyrazolin-5-one bearing thiazolidin4-ones on liver function. Methods. Organic synthesis: multicomponent reactions (MCRs), [2+3]-cycloaddition reactions. Spectral methods: IR, LC-MS, ${ }^{1} \mathrm{H}$ NMR. Biological methods: study of anti-cancer activity (NCI NIH, USA) protocol for 3-cell line panel); carrageenin-induced inflammatory paw edema model of white rats, biochemical laboratory tests (ALT, AST, ALP, $\gamma$-GGT levels determination); evaluation of ulcerogenic action. Results. The series of novel C-5 and N-3 substituted 2-[(1,5-dimethyl-3-oxo-2-phenyl-2,3-dihydro-1H-pyrazol-4-yl) amino/imino]thiazolidin-4-ones had been synthesized using MCR and [2+3]-cycloaddition reactions as potential biologically active compounds. The results of screening anti-exudative activity revealed that the tested derivatives possess promising anti-inflammatory effect. The SARs were formed and possible mechanisms of their action were discussed. Conclusions. The results presented in paper suggest that the design and synthesis of new pyrazolin-5-on/ thiazolidin-4-one hybrids as potential molecules are an attractive area for the search for novel agents with promising pharmacological properties.
\end{abstract}

Ke y w o r d s: antipyrine, pyrazolin-5-one, thiazolidin-4-one, hybrids, multicomponent reactions, tautomers/rotamers; anticancer/anti-inflammatory activity

C 2021 S. M. Holota et al.; Published by the Institute of Molecular Biology and Genetics, NAS of Ukraine on behalf of Biopolymers and Cell. This is an Open Access article distributed under the terms of the Creative Commons Attribution License (http://creativecommons.org/licenses/by/4.0/), which permits unrestricted reuse, distribution, and reproduction in any medium, provided the original work is properly cited 


\section{Introduction}

The pyrazolin-5-one scaffold is one of the oldest in medicinal chemistry and at the same time it does not lose its relevance and attractiveness for researchers. It could be aptly demonstrated by the examples of two worldknown drugs Antypyrine (Phenazone) [1] and Radicava (Edavaron) [2] (Fig. 1), which belong to the simplest pyrazolin-5-one derivatives but were introduced in pharmaceutical market with a difference of almost 120 years and represent different pharmacological groups. Nowadays pyrazolin-5-ones possess important place as a privilege heterocycles $[3,4]$. The pharmacological profile of these compounds is very wide, they are targeted to the treatment and improvement of many difficult pathologies and diseases. The novel molecules with pyrazolin-5-one/antipyryl-4 pharmacophore have been designed, synthesized and successfully studied as selective inhibitors to plausible anti-cancers targets such as vascular endothelial growth factor receptor 2 (VEGFR-2) [5, 6]; c-mesenchymal epithelial transition factor (c-Met) $[7,8]$; Sirtuins (SIRTs) [9]; they display high and selective cytotoxic activity in the in vitro models [10]. Noteworthy, some pyrazolin5-one/antipyr-4-yl bearing compounds are promising as lipid-lowering [11] and antihyperglycemic [12] agents.

The anti-inflammatory action/activity still remains an actual trend in the design of potential non-steroidal anti-inflammatory drugs (NSAIDs) using pyrazoline-5-one/antipyr4-yl scaffold for more than 100 years of synthetic work. Nowadays the fragment/structure-based drug design (F/SBDD) [13] and hybrid-pharmocophore approach (HPhA) are useful tools for design of new drug-like molecules in this area of medicinal chemistry [14]. So, the pyrazolin-5-one bearing thiazolidin-4-one hybrids with promising anti-inflammatory (anti-exudative) activity in carrageenan/formaldehyde-induced inflammatory paw edema models of white rats with low-toxicity parameters have been synthesized and reported [15-18] (Fig. 1) using F/SBDD and/ or HPhA methodologies.

The oxidative stress [19-21] and redox [22, 23] processes play important role under inflammation condition. The ability of neutralization of the impacts of reactive element species (Oxygen, Nitrogen, free radicals) is a desirable feature for modern NSAIDs [24, 25]. That is why an of the chemical groups with anti-scavenging/anti-oxidant or redox properties into

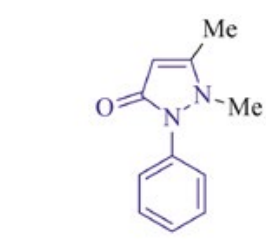

Antipyrine (Phenazone) Ludwig Knorr, 1883, synthesis Hoechst, 1887 , production

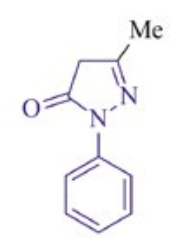

Radicava $^{\infty}$ (Edavaron), Mitsubishi Pharma, 2001

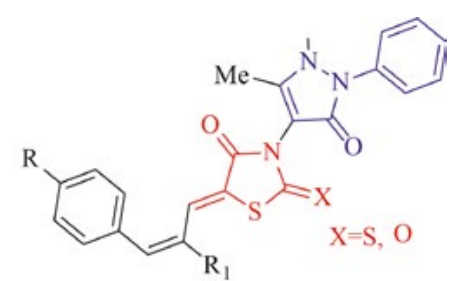

Anti-inflammatory activity in vitro Lesyk R. et. al. 1999, 2002, 2005
Fig. 1. Pyrazolin-5-one motif in drug design. 
the molecular structure of potential NSAIDs seems an attractive strategy for design. Taking into account the above-mentioned reasons and accordingly to our permanent interest to issues of medicinal chemistry of azoles [26-28], here in we report synthetic approaches to novel 5-substituted thiazolidin-4-ones with 4-aminoantipyrine fragments in the $\mathrm{C}-2$ position of heterocycle, their characterization and biological evaluation.

\section{Materials and Methods}

Commercial reagents were purchased from Merck and used without purification. Melting points were measured in open capillary tubes on a BÜCHI B-545 melting point apparatus and are uncorrected. The elemental analyses $(\mathrm{C}, \mathrm{H}, \mathrm{N})$ were performed using the PerkinElmer $2400 \mathrm{CHN}$ analyzer; the results were within $\pm 0.4 \%$ of the theoretical values. The ${ }^{1} \mathrm{H}-\mathrm{NMR}$ spectra were recorded on a Varian Gemini spectrometer at $400 \mathrm{MHz}$ using a mixture of DMSO- $d_{6}+\mathrm{CCl}_{4}$ as a solvent and TMS as an internal standard. Chemical shift values are reported in ppm units with use of $\delta$ scale. Mass spectra were obtained using electrospray ionization (ESI) techniques on Agilent 1100 Series LCMS (column SUPELCO Ascentis Express C18 $2.7 \mu \mathrm{m}, 4.6 \mathrm{~mm} \times 15 \mathrm{~cm}$, solvent - methanol). Infra-red spectra were recorded on OMNIC-510 spectrometer in $\mathrm{KBr}$ pellets. The purity of the compounds was checked by thin-layer chromatography performed with Merck Silica Gel $60 \mathrm{~F}_{254}$ aluminum sheets. Spots were detected by their absorption under UV light.

General synthetic procedure for compounds 4-6, 16-19. A mixtures of compound 2 or $3(10 \mathrm{mmol})$ and maleic anhydride
(10 mmol) or appropriate $\mathrm{N}$-arylmaleimides $(10 \mathrm{mmol})$ were refluxed for $2 \mathrm{~h}$ in $10 \mathrm{ml}$ of glacial acetic acid. After cooling to room temperature, reaction mixtures were filtered off, washed with methanol and recrystallized with acetic acid (5-15 $\mathrm{ml})$.

General synthetic procedure for compounds 7-15. A mixtures of compound 2 $(10 \mathrm{mmol})$, chloroacetic acid $(10 \mathrm{mmol})$, the appropriate oxocompounds $(12 \mathrm{mmol})$ and anhydrous sodium acetate $(20 \mathrm{mmol})$ was refluxed for $3 \mathrm{~h}$ in glacial acetic acid $(10 \mathrm{ml})$. The obtained powders were filtered off, washed with mixture DMF:ethanol (1:3).

2-(2-((1,5-Dimethyl-3-oxo-2-phenyl2,3-dihydro-1H-pyrazol-4-yl)amino)-4oxo-4,5-dihydrothiazol-5-yl)-N-phenylacetamide (4). Yield $57 \%$, $\mathrm{mp}>250{ }^{\circ} \mathrm{C}$. Ratio of amine:imine forms 60:40. ${ }^{1} \mathrm{H}$ NMR, $\delta: 13.00(\mathrm{~s}, 1 \mathrm{H}$, $\mathrm{NH}$, amid), 11.10, 10.40 (2*brs, $1 \mathrm{H}$, $\mathrm{NH}$, amine/imine), 7.47-7.55, 7.29-7.44 (2*m, 10H, arom), 4.27-4.31, 4.16-4.20 $\left(2 * \mathrm{~m}, 1 \mathrm{H}, \mathrm{CH}-\mathrm{CH}_{2}\right), 3.07-3.11,2.76-$ $2.81,2.59-2.65\left(2 * \mathrm{~m}, 2 \mathrm{H}, \mathrm{CH}-\mathrm{CH}_{2}\right)$, $3.10,3.05\left(2 * \mathrm{~s}, 3 \mathrm{H}, \mathrm{N}-\mathrm{CH}_{3}\right), 2.18,2.26$ $\left(2 * \mathrm{~s}, 3 \mathrm{H},=\mathrm{C}-\mathrm{CH}_{3}\right)$. LC-MS (ESI +$) \mathrm{m} / \mathrm{z}$ $436.3(\mathrm{M}+\mathrm{H})^{+}$. Anal. Calc. for $\mathrm{C}_{22} \mathrm{H}_{21} \mathrm{~N}_{5} \mathrm{O}_{3} \mathrm{~S}: \mathrm{C}, 60.68 \%$; H, $4.86 \%$; $\mathrm{N}, 16.08 \%$. Found: C, $60.80 \% ; \mathrm{H}$, $5.00 \% ; \mathrm{N}, 16.20 \%$.

N-(4-Chlorophenyl)-2-(2-((1,5dimethyl-3-oxo-2-phenyl-2,3-dihydro-1H-pyrazol-4-yl)amino)4-oxo-4,5-dihydrothiazol-5-yl)acetamide (5). Yield $72 \%, \mathrm{mp}>250{ }^{\circ} \mathrm{C}$. Ratio of amine:imine forms 50:50. ${ }^{1} \mathrm{H}$ NMR, $\delta: 13.30(\mathrm{~s}, 1 \mathrm{H}, \mathrm{NH}$, amid), $11.20,10.40,10.10(2 *$ brs + s, $1 \mathrm{H}, \mathrm{NH}$, 
amine/imine), $7.58(\mathrm{t}, 1 \mathrm{H}$, arom), 7.42 7.52, 7.20-7.30 (2*m, 6H, arom) 7.36 (d, $2 \mathrm{H}, J=7.8 \mathrm{~Hz}$, arom), 4.36-4.40, 4.21-4.27 (2*m, 1H, CH-CH $\left.{ }_{2}\right), 3.25-$ $3.30,2.87-2.92,2.78-2.81(3 * \mathrm{~m}, 2 \mathrm{H}$, $\left.\mathrm{CH}-\mathrm{CH}_{2}\right), 3.20,3.10\left(2 * \mathrm{~s}, 3 \mathrm{H}, \mathrm{N}-\mathrm{CH}_{3}\right)$, 2.30, 2.25, $2.20\left(3 * \mathrm{~s}, 3 \mathrm{H},=\mathrm{C}-\mathrm{CH}_{3}\right)$. LC$\mathrm{MS}(\mathrm{ESI}+) \mathrm{m} / z$ 471.2 (M+H) ${ }^{+}$. Anal. Calc. for $\mathrm{C}_{22} \mathrm{H}_{20} \mathrm{ClN}_{5} \mathrm{O}_{3} \mathrm{~S}$ : C, $56.23 \%$; $\mathrm{H}, 4.29 \%$; N, 14.90\%. Found: C, $56.40 \%$; H, $4.50 \%$; N, $15.10 \%$.

N-(4-Bromophenyl)-2-(2-((1,5dimethyl-3-oxo-2-phenyl-2,3-dihydro-1H-pyrazol-4-yl)amino)4-oxo-4,5-dihydrothiazol-5-yl)acetamide (6). Yield $79 \%, \mathrm{mp}>220{ }^{\circ} \mathrm{C}$. Ratio of amine:imine forms $60: 40 .{ }^{1} \mathrm{H}$ NMR, $\delta: 10.20(\mathrm{~s}, 1 \mathrm{H}, \mathrm{NH}$, amine/ imine $), 7.47-7.55,7.29-7.44(2 * \mathrm{~m}, 9 \mathrm{H}$, arom), 4.48-4.51, 4.34-4.38 (2*m, $1 \mathrm{H}$, $\mathrm{CH}-\mathrm{CH}_{2}$ ), 3.30-3.34, 3.24-3.27, 2.76$2.81\left(3 * \mathrm{~m}, 2 \mathrm{H}, \mathrm{CH}-\mathrm{CH}_{2}\right), 3.15,3.10$ $\left(2 * \mathrm{~s}, 3 \mathrm{H}, \mathrm{N}-\mathrm{CH}_{3}\right), 2.26,2.18(2 * \mathrm{~s}, 3 \mathrm{H}$, $\left.=\mathrm{C}-\mathrm{CH}_{3}\right)$. LC-MS (ESI+) $\mathrm{m} / z 515.4$ $(\mathrm{M}+\mathrm{H})^{+}$. Anal. Calc. for $\mathrm{C}_{22} \mathrm{H}_{20} \mathrm{BrN}_{5} \mathrm{O}_{3} \mathrm{~S}$ : C, $51.37 \%$; H, $3.92 \%$; N, $13.61 \%$. Found: C, $52.40 \%$; H, $4.00 \%$; N, $13.80 \%$.

(Z)-5-Benzylidene-2-((1,5-dimethyl3-oxo-2-phenyl-2,3-dihydro-1H-pyrazol-4-yl)amino)thiazol-4(5H)-one (7). Yield $41 \%, \operatorname{mp~} 237-238^{\circ} \mathrm{C}$. Ratio of amine:imine forms 60:40. ${ }^{1} \mathrm{H}$ NMR, $\delta$ : 13.00, $9.10(2 *$ brs, $1 \mathrm{H}, \mathrm{NH}$, amine/imine), $7.80(\mathrm{~s}, 1 \mathrm{H},=\mathrm{CH}), 7.41-7.54,7.25-$ $7.39(2 * \mathrm{~m}, 10 \mathrm{H}$, arom $), 3.19,3.09(2 * \mathrm{~s}$, $\left.3 \mathrm{H}, \mathrm{N}-\mathrm{CH}_{3}\right), 2.31,2.21(2 * \mathrm{~s}, 3 \mathrm{H},=\mathrm{C}-$ $\left.\mathrm{CH}_{3}\right)$. IR $\left(\mathrm{KBr}, \mathrm{cm}^{-1}\right): 3376(\mathrm{vNH}), 1720$ $(v C=\mathrm{O}), 1628(v \mathrm{C}=\mathrm{N})$ imine-form; 3360 $(v \mathrm{NH}) 1660(v \mathrm{C}=\mathrm{O}), 1608(v \mathrm{C}=\mathrm{N})$ amine-form; 3080 ( $v \mathrm{CH}), 1684,1576$ $(v \mathrm{C}=\mathrm{O}, v \mathrm{C}=\mathrm{N}$ pyrazol $), 1516(\mathrm{vC}=\mathrm{C})$, $1344(\delta \mathrm{CH}), 716(v \mathrm{C}-\mathrm{S}), 652(v \mathrm{C}-\mathrm{S}-\mathrm{C})$, 769, $696(\delta \mathrm{CH}, \mathrm{ArH})$. LC-MS (ESI+) $m / z 391.4(\mathrm{M}+\mathrm{H})^{+}$. Anal. Calc. for $\mathrm{C}_{21} \mathrm{H}_{18} \mathrm{~N}_{4} \mathrm{O}_{2} \mathrm{~S}: \mathrm{C}, 64.60 \%$; $\mathrm{H}, 4.65 \%$; $\mathrm{N}, 14.35 \%$. Found: C, $64.80 \% ; \mathrm{H}$, $4.80 \% ; \mathrm{N}, 14.50 \%$.

(Z)-2-((1,5-Dimethyl-3-oxo-2phenyl-2,3-dihydro-1H-pyrazol-4-yl) amino)-5-(4-hydroxybenzylidene)thiazol-4(5H)-one (8). Yield $54 \%$, $\mathrm{mp}>250^{\circ} \mathrm{C}$. Ratio of amine:imine forms 75:25. ${ }^{1} \mathrm{H}$ NMR, $\delta: 13.60,11.80,10.70$ ( $3 *$ brs, $1 \mathrm{H}, \mathrm{NH}$, amine/imine), 10.19 , 9.91, $9.90\left(3^{*} \mathrm{~s}, 1 \mathrm{H}, \mathrm{OH}\right), 7.88(\mathrm{~s}, 1 \mathrm{H}$, $=\mathrm{CH}), 7.43-7.52 \mathrm{~m}, 7.28-7.40(\mathrm{~m}, 5 \mathrm{H}$, arom), $6.91(\mathrm{~d}, 2 \mathrm{H}, J=7.9 \mathrm{~Hz}$, arom), $6.87(\mathrm{~d}, 2 \mathrm{H}, J=7.9 \mathrm{~Hz}$, arom), 3.29, $3.23\left(2 * \mathrm{~s}, 3 \mathrm{H}, \mathrm{N}-\mathrm{CH}_{3}\right), 2.37,2.24(2 * \mathrm{~s}$, $\left.3 \mathrm{H},=\mathrm{C}-\mathrm{CH}_{3}\right)$. IR $\left(\mathrm{KBr}, \mathrm{cm}^{-1}\right): 3384$ $(v \mathrm{NH}), 1720(v \mathrm{C}=\mathrm{O}), 1652(v \mathrm{C}=\mathrm{N})$ imine-form; $3360(\mathrm{vNH}) 1672(\mathrm{vC}=\mathrm{O})$, $1596(\mathrm{vC}=\mathrm{N})$ amine-form; $3632(\mathrm{vOH})$, $3080(v \mathrm{CH}), 1684,1524(v \mathrm{C}=\mathrm{O}, v \mathrm{C}=\mathrm{N}$ pyrazol), $1340(\delta \mathrm{CH}), 1508(\vee \mathrm{C}=\mathrm{C})$, $1156(\delta \mathrm{C}-\mathrm{O}), 760(\delta \mathrm{CH}, \mathrm{ArH}) 720(\mathrm{vC}-$ S), $656(v C-S-C)$. LC-MS (ESI+) $m / z$ $407.3(\mathrm{M}+\mathrm{H})^{+}$. Anal. Calc. for $\mathrm{C}_{21} \mathrm{H}_{18} \mathrm{~N}_{4} \mathrm{O}_{3} \mathrm{~S}$ : C, $62.06 \%$; H, $4.46 \%$; $\mathrm{N}, 13.78 \%$. Found: C, $62.30 \%$, $4.60 \% ; \mathrm{N}, 13.90 \%$.

(Z)-5-(4-Chlorobenzylidene)-2-((1,5dimethyl-3-oxo-2-phenyl-2,3-dihydro-1H-pyrazol-4-yl)amino)thiazol4(5H)-one (9). Yield $62 \%, \mathrm{mp}>250{ }^{\circ} \mathrm{C}$. Ratio of amine:imine forms $50: 50 .{ }^{1} \mathrm{H}$ NMR, $\delta: 11.70,10.55$ (2*brs, 1H, NH, 
amine/imine), $7.64(\mathrm{~s}, 1 \mathrm{H},=\mathrm{CH}), 7.47-$ 7.54, 7.32-7.43 (2*m, 5H, arom), 7.25 (d, $2 \mathrm{H}, J=8.1 \mathrm{~Hz}$, arom), $7.20(\mathrm{~d}, 2 \mathrm{H}$, $J=8.1 \mathrm{~Hz}$, arom $), 3.27,3.19(2 * \mathrm{~s}, 3 \mathrm{H}$, $\left.\mathrm{N}-\mathrm{CH}_{3}\right), 2.31,2.19\left(2 * \mathrm{~s}, 3 \mathrm{H},=\mathrm{C}-\mathrm{CH}_{3}\right)$. LC-MS (ESI+) $m / z 426.5(\mathrm{M}+\mathrm{H})^{+}$. Anal. Calc. for $\mathrm{C}_{21} \mathrm{H}_{17} \mathrm{ClN}_{4} \mathrm{O}_{2} \mathrm{~S}$ : C, $59.36 \%$; $\mathrm{H}, 4.03 \%$; N, $13.19 \%$. Found: C, $59.50 \%$; H, $4.20 \%$; N, $13.30 \%$.

(Z)-5-(4-Bromobenzylidene)-2-((1,5dimethyl-3-oxo-2-phenyl-2,3-dihydro-1H-pyrazol-4-yl)amino)thiazol4(5H)-one (10). Yield $57 \%, \mathrm{mp}>250^{\circ} \mathrm{C}$. Ratio of amine:imine forms 50:50. ${ }^{1} \mathrm{H}$ NMR, $\delta: 14.00,12.00,9.50,9.30$ (2* brs $+2 * \mathrm{~s}, 1 \mathrm{H}, \mathrm{NH}$, amine/imine), $7.68-$ 7.74, 7.48-7.62, 7.33-7.43 (3*m, 10H, $=\mathrm{CH}+$ arom $), 3.21,3.13(2 * \mathrm{~s}, 3 \mathrm{H}$, $\left.\mathrm{N}-\mathrm{CH}_{3}\right), 2.32,2.22\left(2 * \mathrm{~s}, 3 \mathrm{H},=\mathrm{C}-\mathrm{CH}_{3}\right)$. LC-MS (ESI+) $m / z 470.2(\mathrm{M}+\mathrm{H})^{+}$. Anal. Calc. for $\mathrm{C}_{21} \mathrm{H}_{17} \mathrm{BrN}_{4} \mathrm{O}_{2} \mathrm{~S}$ : C, $53.74 \%$; $\mathrm{H}, 3.65 \%$; N, $11.94 \%$. Found: C, $53.90 \%$; H, $3.80 \%$; N, $12.10 \%$.

(Z)-2-((1,5-Dimethyl-3-oxo-2phenyl-2,3-dihydro-1H-pyrazol-4-yl) amino)-5-(4-methoxybenzylidene)thiazol-4(5H)-one (11). Yield $62 \%$, $\mathrm{mp}=201-204{ }^{\circ} \mathrm{C}$. Ratio of amine:imine forms 74:26. ${ }^{1} \mathrm{H} \mathrm{NMR}, \delta: 13.30,9.00$ (brs $+\mathrm{s}, 1 \mathrm{H}, \mathrm{NH}$, amine/imine), 7.95 (s, $1 \mathrm{H},=\mathrm{CH}), 7.61(\mathrm{~d}, 2 \mathrm{H}, J=7.6 \mathrm{~Hz}$, arom $), 7.45-7.59,7.30-7.42(2 * \mathrm{~m}$, arom) $7.10(\mathrm{~d}, 2 \mathrm{H}, J=7.3 \mathrm{~Hz}$, arom), $7.05(\mathrm{t}, 1 \mathrm{H}, J=7.9 \mathrm{~Hz}$, arom), 3.84, $3.83,3.82\left(3^{*} \mathrm{~s}, 3 \mathrm{H}, \mathrm{OCH}_{3}\right), 3.28,3.22$, $3.12\left(3 * \mathrm{~s}, 3 \mathrm{H}, \mathrm{N}-\mathrm{CH}_{3}\right), 2.33,2.24,2.23$ $\left(3 * \mathrm{~s}, 3 \mathrm{H},=\mathrm{C}-\mathrm{CH}_{3}\right)$. IR $\left(\mathrm{KBr}, \mathrm{cm}^{-1}\right)$ : $3384(v \mathrm{NH}), 1720(v \mathrm{C}=\mathrm{O}), 1636(v \mathrm{C}=\mathrm{N})$ imine-form; $3365(v \mathrm{NH}) 1664(\mathrm{vC}=\mathrm{O})$,
$1592(\mathrm{vC}=\mathrm{N})$ amine-form; $3096(\mathrm{vCH})$, $2860\left(v \mathrm{O}-\mathrm{CH}_{3}\right), 1680,1576(v \mathrm{C}=\mathrm{O}$, $v \mathrm{C}=\mathrm{N}$ pyrazol $), 1512(v \mathrm{C}=\mathrm{C}), 1348$ $(\delta \mathrm{CH}), 764,680(\delta \mathrm{CH}, \mathrm{ArH}), 712(\mathrm{vC}-$ S), $648(v C-S-C)$. LC-MS (ESI+) $\mathrm{m} / z$ $421.7(\mathrm{M}+\mathrm{H})^{+}$. Anal. Calc. for $\mathrm{C}_{22} \mathrm{H}_{20} \mathrm{~N}_{4} \mathrm{O}_{3} \mathrm{~S}$ : C, $62.84 \%$; H, $4.79 \%$; N, $13.32 \%$. Found: C, $62.90 \%$; H, 5.00 $\%$; N, $13.50 \%$.

(Z)-2-((1,5-Dimethyl-3-oxo-2phenyl-2,3-dihydro-1H-pyrazol-4-yl) a m i no ) - 5 - ( 4 - hydroxy - 3 methoxybenzylidene)thiazol-4(5H)-one (12). Yield $46 \%, \mathrm{mp}>250{ }^{\circ} \mathrm{C}$. Ratio of amine:imine forms 70:30. ${ }^{1} \mathrm{H}$ NMR, $\delta$ : $13.00,10.20$ (brs $+\mathrm{s}, 1 \mathrm{H}, \mathrm{NH}$, amine/ imine $), 9.25,9.00(2 * \mathrm{~s}, 1 \mathrm{H}, \mathrm{OH}), 7.75$ $(\mathrm{s}, 1 \mathrm{H},=\mathrm{CH}), 7.40-7.55,7.20-7.35$ (2*m, arom), $7.13(\mathrm{~d}, 2 \mathrm{H}, J=7.2 \mathrm{~Hz}$, arom $), 3.75,3.68\left(2 * \mathrm{~s}, 3 \mathrm{H}, \mathrm{OCH}_{3}\right)$, $3.25,3.13\left(2 * \mathrm{~s}, 3 \mathrm{H}, \mathrm{N}-\mathrm{CH}_{3}\right), 2.29,2.19$ $\left(2 * \mathrm{~s}, 3 \mathrm{H},=\mathrm{C}-\mathrm{CH}_{3}\right)$. LC-MS (ESI+) $\mathrm{m} / z$ $437.6(\mathrm{M}+\mathrm{H})^{+}$. Anal. Calc. for $\mathrm{C}_{22} \mathrm{H}_{20} \mathrm{~N}_{4} \mathrm{O}_{4} \mathrm{~S}: \mathrm{C}, 60.54 \% ; \mathrm{H}, 4.62 \%$; N, $12.84 \%$. Found: C, $60.70 \% ; \mathrm{H}$, $4.90 \% ; \mathrm{N}, 13.00 \%$.

(Z)-5-(3,4-Dimethoxybenzylidene)2-((1,5-dimethyl-3-oxo-2-phenyl-2,3dihydro-1H-pyrazol-4-yl)amino)thiazol-4(5H)-one (13). Yield $41 \%$, $\mathrm{mp}=241-243{ }^{\circ} \mathrm{C}$. Ratio of amine:imine forms 70:30. ${ }^{1} \mathrm{H} \mathrm{NMR}, \delta: 12.90,9.00$ ( $2 *$ brs, $1 \mathrm{H}, \mathrm{NH}$, amine/imine), $7.70(\mathrm{~s}$, $1 \mathrm{H},=\mathrm{CH}), 7.40-7.50,7.20-7.35(2 * \mathrm{~m}$, arom), 3.85, 3.83, 3.73, $3.68(4 * \mathrm{~s}, 6 \mathrm{H}$, $\left.2 * \mathrm{OCH}_{3}\right), 3.29,3.18\left(2 * \mathrm{~s}, 3 \mathrm{H}, \mathrm{N}-\mathrm{CH}_{3}\right)$, $2.32,2.23\left(2 * \mathrm{~s}, 3 \mathrm{H},=\mathrm{C}-\mathrm{CH}_{3}\right)$. IR $(\mathrm{KBr}$, $\left.\mathrm{cm}^{-1}\right): 3368(v \mathrm{NH}) 1681(\mathrm{vC}=\mathrm{O}), 1628$ $(v \mathrm{C}=\mathrm{N})$ imine-form; $3352(v \mathrm{NH}), 1664$ 
$(v \mathrm{C}=\mathrm{O}), 1608(v \mathrm{C}=\mathrm{N})$ amine-form; $3069(v \mathrm{CH}), 2856\left(v \mathrm{O}-\mathrm{CH}_{3}\right), 1580$ $(v \mathrm{C}=\mathrm{N}$ pyrazol $), 1518(\mathrm{vC}=\mathrm{C}), 1356$ $(\delta \mathrm{CH}), 772(\delta \mathrm{CH}, \mathrm{ArH}), 716(\mathrm{vC}-\mathrm{S})$, 664 (vC-S-C). LC-MS (ESI+) $m / z 451.5$ $(\mathrm{M}+\mathrm{H})^{+}$. Anal. Calc. for $\mathrm{C}_{23} \mathrm{H}_{22} \mathrm{~N}_{4} \mathrm{O}_{4} \mathrm{~S}$ : C, $61.32 \%$; H, $4.92 \%$; N, $12.44 \%$. Found: C, $61.60 \% ; \mathrm{H}, 5.10 \%$; , $12.70 \%$.

(Z)-2-((1,5-Dimethyl-3-oxo-2phenyl-2,3-dihydro-1H-pyrazol-4-yl) amino)-5-(3-nitrobenzylidene)thiazol4(5H)-one (14). Yield $51 \%, \mathrm{mp}>250^{\circ} \mathrm{C}$. Ratio of amine:imine forms $25: 75 .{ }^{1} \mathrm{H}$ NMR, $\delta: 14.06$ (s, 1H, NH, amine/imine), 8.40, $8.38(2 * \mathrm{~s}, 1 \mathrm{H},=\mathrm{CH}), 8.16-$ 8.24, 7.88-8.00, 7.38-7.60 (3*m, arom) $7.77(\mathrm{t}, 1 \mathrm{H}, J=8.3 \mathrm{~Hz}$, arom), $7.32(\mathrm{t}$, $1 \mathrm{H}, J=8.5 \mathrm{~Hz}$, arom), 3.26, $3.15(2 * \mathrm{~s}$, $\left.3 \mathrm{H}, \mathrm{N}-\mathrm{CH}_{3}\right), 2.38,2.26(2 * \mathrm{~s}, 3 \mathrm{H},=\mathrm{C}-$ $\left.\mathrm{CH}_{3}\right)$. IR (KBr, cm$\left.{ }^{-1}\right): 3376(\mathrm{vNH}), 1728$ $(v \mathrm{C}=\mathrm{O}), 1636(v \mathrm{C}=\mathrm{N})$ imine-form; 3352 $(v \mathrm{NH}) 1664(v \mathrm{C}=\mathrm{O}), 1608(v \mathrm{C}=\mathrm{N})$ amine-form; $3064(\mathrm{vCH}), 1577(\mathrm{vC}=\mathrm{N}$ pyrazol), $1532(v \mathrm{C}=\mathrm{C}), 1352(\delta \mathrm{CH})$, 768, 696 ( $\delta \mathrm{CH}, \mathrm{ArH}), 712(v \mathrm{C}-\mathrm{S}), 664$ (vC-S-C). LC-MS (ESI+) $\mathrm{m} / z \quad 436.4$ $(\mathrm{M}+\mathrm{H})^{+}$. Anal. Calc. for $\mathrm{C}_{21} \mathrm{H}_{17} \mathrm{~N}_{5} \mathrm{O}_{4} \mathrm{~S}$ : C, $57.92 \%$; H, $3.94 \%$; N, $16.08 \%$. Found: C, $58.00 \% ; \mathrm{H}, 4.10 \%$; $16.20 \%$.

(Z)-2-((1,5-Dimethyl-3-oxo-2phenyl-2,3-dihydro-1H-pyrazol-4-yl) amino)-5-((E/Z)-3-phenylallylidene) thiazol-4(5H)-one (15). Yield $58 \%$, $\mathrm{mp}=194-197^{\circ} \mathrm{C}$. Ratio of amine:imine forms $60: 40 .{ }^{1} \mathrm{H}$ NMR, $\delta: 13.72,11.81$, $10.69(\mathrm{~s}+2 *$ brs, $1 \mathrm{H}, \mathrm{NH}$, amine/imine), 7.46-7.60, 7.27-7.43, 7.07-7.15, 6.80-
$6.88(4 * \mathrm{~m}, \operatorname{arom}+\mathrm{CH}=\mathrm{CH}-\mathrm{CH}=), 3.20$, $3.19,3.10\left(3 * \mathrm{~s}, 3 \mathrm{H}, \mathrm{N}-\mathrm{CH}_{3}\right), 2.35,2.21$ $\left(2 * \mathrm{~s}, 3 \mathrm{H},=\mathrm{C}-\mathrm{CH}_{3}\right)$. LC-MS (ESI+) $\mathrm{m} / z$ $417.3(\mathrm{M}+\mathrm{H})^{+}$. Anal. Calc. for $\mathrm{C}_{23} \mathrm{H}_{20} \mathrm{~N}_{4} \mathrm{O}_{2} \mathrm{~S}$ : C, $66.33 \%$; H, $4.84 \%$; N, $13.45 \%$. Found: C, $66.50 \% ; \mathrm{H}$, $5.10 \% ; \mathrm{N}, 13.60 \%$.

2-(3-Allyl-2-((1,5-dimethyl-3-oxo-2phenyl-2,3-dihydro-1H-pyrazol-4-yl) amino)-4-oxothiazolidin-5-yl)acetic acid (16). Yield $74 \%, \mathrm{mp}=200-203{ }^{\circ} \mathrm{C}$. ${ }^{1} \mathrm{H}$ NMR, $\delta: 12.5$ (brs, 1H, COOH), 7.50 (t, $1 \mathrm{H}, J=8.5 \mathrm{~Hz}$, arom), $7.40(\mathrm{t}, 2 \mathrm{H}$, $J=8.7 \mathrm{~Hz}$, arom), $7.20(\mathrm{~d}, 2 \mathrm{H}, J=$ $7.7 \mathrm{~Hz}$, arom), 5.86-5.90 (m, 1H, allyl), $5.30(\mathrm{~d}, 1 \mathrm{H}, J=1.6 \mathrm{~Hz}$, allyl), $5.20(\mathrm{~d}$, $1 \mathrm{H}, J=1.6 \mathrm{~Hz}$, allyl), 4.40 (d, 2H, $J=$ $1.7 \mathrm{~Hz}$, allyl), 4.46-4.50 (m, $1 \mathrm{H}, \mathrm{CH}-$ $\left.\mathrm{CH}_{2}\right), 3.20(\mathrm{dd}, 1 \mathrm{H}, J=18.0 \mathrm{~Hz}, J=$ $\left.7.5 \mathrm{~Hz}, \mathrm{CH}-\mathrm{CH}_{2}\right), 2.80(\mathrm{dd}, 1 \mathrm{H}, J=$ $\left.18.0 \mathrm{~Hz}, J=5.0 \mathrm{~Hz}, \mathrm{CH}-\mathrm{CH}_{2}\right), 3.00(\mathrm{~s}$, $\left.3 \mathrm{H}, \mathrm{N}-\mathrm{CH}_{3}\right), 2.10\left(\mathrm{~s}, 3 \mathrm{H},=\mathrm{C}-\mathrm{CH}_{3}\right)$. LCMS (ESI+) $m / z 403.8(\mathrm{M}+\mathrm{H})^{+}$. Anal. Calc. for $\mathrm{C}_{19} \mathrm{H}_{22} \mathrm{~N}_{4} \mathrm{O}_{4} \mathrm{~S}$ : C, $56.70 \% ; \mathrm{H}$, $5.51 \%$; N, $13.92 \%$. Found: C, $56.80 \%$; $\mathrm{H}, 5.70 \%$; N, $14.00 \%$.

2-(3-Allyl-2-((1,5-dimethyl-3-oxo-2phenyl-2,3-dihydro-1H-pyrazol-4-yl) amino)-4-oxothiazolidin-5-yl)-N-phenylacetamide (17). Yield $63 \%, \mathrm{mp}=184-$ $186{ }^{\circ} \mathrm{C} .{ }^{1} \mathrm{H}$ NMR, $\delta: 9.90$ (s, 1H, NH), 7.00-7.60 (m, arom), 5.86-5.90 (m, 1H, allyl), (d, $1 \mathrm{H}, J=1.6 \mathrm{~Hz}$, allyl), 5.20 (d, $1 \mathrm{H}, J=1.6 \mathrm{~Hz}$, allyl), 4.40 (d, 2H, $J=$ $1.7 \mathrm{~Hz}$, allyl), 4.46-4.50 (m, $1 \mathrm{H}, \mathrm{CH}-$ $\left.\mathrm{CH}_{2}\right), 3.30(\mathrm{dd}, 1 \mathrm{H}, J=17.8 \mathrm{~Hz}$, $\left.J=7.6 \mathrm{~Hz}, \mathrm{CH}-\mathrm{CH}_{2}\right), 2.50(\mathrm{dd}, 1 \mathrm{H}, J=$ $\left.17.9 \mathrm{~Hz}, J=4.8 \mathrm{~Hz}, \mathrm{CH}-\mathrm{CH}_{2}\right), 3.00(\mathrm{~s}$, $\left.3 \mathrm{H}, \mathrm{N}-\mathrm{CH}_{3}\right), 2.20\left(\mathrm{~s}, 3 \mathrm{H},=\mathrm{C}-\mathrm{CH}_{3}\right) . \mathrm{LC}-$ 
MS (ESI+) $m / z 478.4(\mathrm{M}+\mathrm{H})^{+}$. Anal. Calc. for $\mathrm{C}_{25} \mathrm{H}_{27} \mathrm{~N}_{5} \mathrm{O}_{3} \mathrm{~S}$ : C, 62.87; $\mathrm{H}$, $5.70 ; \mathrm{N}, 14.66 \%$. Found: C, $63.00 \%$; $\mathrm{H}, 5.90 \%$; N, $14.80 \%$.

2-(3-Allyl-2-((1,5-dimethyl-3-oxo-2phenyl-2,3-dihydro-1H-pyrazol-4-yl) amino)-4-oxothiazolidin-5-yl)-N-(4chlorophenyl)acetamide (18). Yield $63 \%, \mathrm{mp}=193-196{ }^{\circ} \mathrm{C} .{ }^{1} \mathrm{H}$ NMR, $\delta$ : $10.10(\mathrm{~s}, 1 \mathrm{H}, \mathrm{NH}), 7.40-7.60$ (m, arom) $7.32(\mathrm{t}, 1 \mathrm{H}, J=8.7 \mathrm{~Hz}$, arom $), 7.18(\mathrm{t}$, $2 \mathrm{H}, J=7.5 \mathrm{~Hz}$, arom $), 5.86-5.90(\mathrm{~m}, 1 \mathrm{H}$, allyl), (d, $1 \mathrm{H}, J=1.7 \mathrm{~Hz}$, allyl), 5.20 (d, $1 \mathrm{H}, J=1.7 \mathrm{~Hz}$, allyl), 4.40 (d, $2 \mathrm{H}, J=$ $1.7 \mathrm{~Hz}$, allyl), 4.48-4.51 (m, 1H, CH$\left.\mathrm{CH}_{2}\right), 3.30(\mathrm{dd}, 1 \mathrm{H}, J=18.2 \mathrm{~Hz}, J=$ $\left.7.4 \mathrm{~Hz}, \mathrm{CH}-\mathrm{CH}_{2}\right), 2.80(\mathrm{dd}, 1 \mathrm{H}, J=$ $\left.18.1 \mathrm{~Hz}, J=5.1 \mathrm{~Hz}, \mathrm{CH}-\mathrm{CH}_{2}\right), 3.00$ (s, $\left.3 \mathrm{H}, \mathrm{N}-\mathrm{CH}_{3}\right), 2.10\left(\mathrm{~s}, 3 \mathrm{H},=\mathrm{C}-\mathrm{CH}_{3}\right)$. LCMS (ESI+) $m / z 513.2(\mathrm{M}+\mathrm{H})^{+}$. Anal. Calc. for $\mathrm{C}_{25} \mathrm{H}_{26} \mathrm{ClN}_{5} \mathrm{O}_{3} \mathrm{~S}: \mathrm{C}, 58.64 \%$; $\mathrm{H}, 5.12 \%$; N, $13.68 \%$. Found: C, $58.80 \%$; H, $5.30 \%$; N, $13.80 \%$.

2-(3-Allyl-2-((1,5-dimethyl-3-oxo-2phenyl-2,3-dihydro-1H-pyrazol-4-yl) amino)-4-oxothiazolidin-5-yl)-N-(4bromophenyl)acetamide (19). Yield $61 \%, \mathrm{mp}=196-198{ }^{\circ} \mathrm{C} .{ }^{1} \mathrm{H} \mathrm{NMR}, \delta$ : 10.00 (s, 1H, NH), 7.40-7.60, 7.25-7.38 (m, 9H, arom), 5.86-5.90 (m, 1H, allyl), (d, $1 \mathrm{H}, J=1.7 \mathrm{~Hz}$, allyl), $5.20(\mathrm{~d}, 1 \mathrm{H}$, $J=1.7 \mathrm{~Hz}$, allyl), $4.40(\mathrm{~d}, 2 \mathrm{H}, J=$ $1.7 \mathrm{~Hz}$, allyl), 4.45-4.49 (m, 1H, CH$\left.\mathrm{CH}_{2}\right), 3.20(\mathrm{dd}, 1 \mathrm{H}, J=18.0 \mathrm{~Hz}, J=$ $\left.7.3 \mathrm{~Hz}, \mathrm{CH}-\mathrm{CH}_{2}\right), 2.70(\mathrm{dd}, 1 \mathrm{H}, J=$ $\left.18.0 \mathrm{~Hz}, J=4.9 \mathrm{~Hz}, \mathrm{CH}-\mathrm{CH}_{2}\right) 3.00(\mathrm{~s}$, $\left.3 \mathrm{H}, \mathrm{N}-\mathrm{CH}_{3}\right), 2.15\left(\mathrm{~s}, 3 \mathrm{H},=\mathrm{C}-\mathrm{CH}_{3}\right)$. LCMS (ESI+) $m / z 556.4(\mathrm{M}+\mathrm{H})^{+}$. Anal. Calc. for $\mathrm{C}_{25} \mathrm{H}_{26} \mathrm{BrN}_{5} \mathrm{O}_{3} \mathrm{~S}$ : C, $53.96 \%$;
H, $4.71 \%$; N, $12.59 \%$. Found: C, $54.10 \%$; H, $5.00 \%$; N, $12.80 \%$.

Anticancer assay. A primary anticancer assay was performed in the 3-cell line panel consisting of NCI-H460 (Lung), MCF7 (Breast) and SF-268 (CNS), in accordance with the protocol of the Drug Evaluation Branch, National Cancer Institute, Bethesda $[29,30]$.

Anti-inflammatory (antiexudative) assay. The male albino rats weighing 180-220 g were used for studying the anti-exudative activity. The animals were treated humanely throughout the study period adhering to the guideline for use and care of animals in declaration of Helsinki (National Research Council, 2011). The experiment design and study protocol were approved by the Animal Ethics Committee of the Danylo Halytsky Lviv National Medical University, protocol No. 4, January 23, 2020. The carrageenaninduced hind paw oedema was produced by the method of Winter et al. [31].

Assessment of liver function. The serum collected from the albino rats was used for estimation of biochemical parameters to determine the functional state of the liver.

Estimation of ulcerogenic activity. The estimation of ulcerogenic activity was performed according to recommendations [32].

\section{Results and Discussion}

\section{Chemistry}

The 4-amino-1,5-dimethyl-2-phenyl-1,2-dihydro-3H-pyrazol-3-one (4-aminoantipyrine, 1) was used as a starting reagent for synthesis of target derivatives 4-19 (Scheme 1) accordingly to selected synthetic strategy. The key 
building block 1-(1,5-dimethyl-3-oxo-2-phenyl-2,3-dihydro-1H-pyrazol-4-yl)thiourea (2) was synthesized from 1 following two-step approach $(\mathbf{a}, \mathbf{b})$. The utilization of $\mathbf{2}$ in [2+3]-cyclocondensation reaction with $\mathrm{N}$-arylmaleimides (c) as well as in three-component one-pot process with chloroacetic acid and aromatic aldehydes (d) efficiently lead to C-5 modified thiazolidin-4-one derivatives $4-6$ and 7-15 respectively. The 1-allyl-3-(1,5-dimethyl3-oxo-2-phenyl-2,3-dihydro-1 $H$-pyrazol-4-yl) thiourea (3) has been obtained in reaction 1 with allyl isothiocyanate (e). The 3-allyl-substituted thiazolidin-4-ones (16-19) were synthesized in $[2+3]$-cyclocondensation reaction of 3 with maleic anhydride (f) and $\mathrm{N}$-arylmaleimides (c).

The ${ }^{1} \mathrm{H}$ NMR, IR spectroscopies and LCMS spectrometry were used for structure determination of the synthesized compounds. The 2-R-imino/amino-thiazolidin-4-ones possess prototropic amine/imine tautomerism [33]. In the ${ }^{1} \mathrm{H}$ NMR spectra of compounds 4-15 the signals of both tautomeric forms were observed. The signals of amine-forms protons of compounds were observed at $9.00-10.70 \mathrm{ppm}$ and the signals of imine-forms protons were observed at 11.0-14.06 ppm. The ratio of tautomers based on the integral intensity curve ranges from $\sim 3: 1$ to $\sim 1: 3$ (amine-imine forms respectively). The correlation of the prevalence amine- or imine-form with electron nature of substituent in C-5 was observed. The presence of electron withdrawing group $\left(\mathrm{NO}_{2}\right.$-group) leads increasing of imine-form whereas the electron releasing groups $(\mathrm{OMe}, \mathrm{OH})$ result in [the] prevalence of amine-form. The ${ }^{1} \mathrm{H}$ NMR spectral patterns of derivatives 5, 8, 10-12, 15 are more complex and the appearance of 3 or
4 groups of signals which belong to possible rotameric forms was observed (Fig. 2). The studies of IR-spectra of compounds 7, 8, 11, 13, 14 confirmed the presence of amine/imine tautomerism in the solid state.

\section{Pharmacology}

\section{Anticancer activity}

The last decades have witnessed a growing interest in the studies of anticancer properties of NSAIDs and compound with anti-inflammatory activity $[34,35]$. The prescreening of anti-cancer activity of compounds 7, 11, 13 was performed according to the US NCI protocol, as described elsewhere [29, 30]. These substances were evaluated in the 3-cell line panel consisting of NCI-H460 (Lung), MCF7 (Breast), and SF-268 (CNS) cell lines. As a result all tested compounds were found inactive and in the pre-screening phase (Table 1). Only compound $\mathbf{1 1}$ showed moderate growth inhibition activity (69\%) against Lung cancer cell line NCI-H460.

Table 1. Anticancer screening (3 cell lines assay) data of compounds $7,11,13$ in $10 \mu \mathrm{M}$ concentration

\begin{tabular}{c|c|c|c}
\hline \multirow{2}{*}{$\begin{array}{c}\text { Compound/ } \\
\text { NCI number }\end{array}$} & \multicolumn{3}{|c}{ Cell lines and growth percent of treated cells, \% } \\
\cline { 2 - 4 } & $\begin{array}{c}\text { NCI-H460, } \\
\text { Lung cancer }\end{array}$ & $\begin{array}{c}\text { SF-268, CNS } \\
\text { cancer }\end{array}$ & $\begin{array}{c}\text { MCF7, breast } \\
\text { cancer }\end{array}$ \\
\hline $\mathbf{7}$ / S730128 & 96 & 117 & 114 \\
\hline $\mathbf{1 1}$ / S729939 & 69 & 87 & 97 \\
\hline $\mathbf{1 3}$ / S730129 & 89 & 115 & 108 \\
\hline
\end{tabular}

Despite, that presented anti-cancer activity results indicate that only derivative 11 possesses low activity, but the presence of one, as well as the prevailing impact on NCI-H460 line (Lung cancer), give opportunities for perspectives of rational design of anticancer 
<smiles>[R]NC(=O)CC1SC(Nc2c(C)n(C)n(-c3ccccc3)c2=O)=NC1=O</smiles>

$$
\begin{aligned}
& \text { R: } 4-\mathrm{C}_{6} \mathrm{H}_{5} \\
& \mathbf{5}-4-\mathrm{Cl}-\mathrm{C}_{6} \mathrm{H}_{4} \\
& \mathbf{6}-4-\mathrm{Br}-\mathrm{C}_{6} \mathrm{H}_{4}
\end{aligned}
$$<smiles>C=CCN1C(=O)C(CC(=O)O)S/C1=N\c1c(C)n(C)n(-c2ccccc2)c1=O</smiles>

16<smiles>[R7]C=C1SC(Nc2c(C)n(C)n(-c3ccccc3)c2=O)=NC1=O</smiles>

7-15

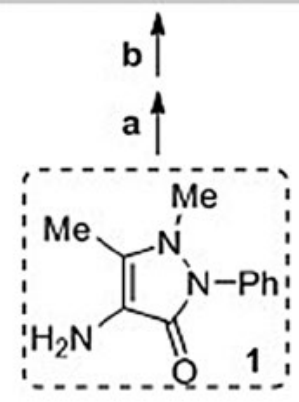

R': $7-\mathrm{C}_{6} \mathrm{H}_{5} ; 8-4-\mathrm{HO}-\mathrm{C}_{6} \mathrm{H}_{4}$;

9 - 4-Cl- $\mathrm{C}_{6} \mathrm{H}_{4} ; 10$ - 4- $\mathrm{Br}-\mathrm{C}_{6} \mathrm{H}_{4}$;

11 - 4-MeO- $\mathrm{C}_{6} \mathrm{H}_{4} ; 12$ - 3-MeO-4- $\mathrm{HO}-\mathrm{C}_{6} \mathrm{H}_{3}$;

13 - 3,4-(MeO) $)_{2}-\mathrm{C}_{6} \mathrm{H}_{3} ; 14$ - 3- $\mathrm{NO}_{2}-\mathrm{C}_{6} \mathrm{H}_{4}$;

$15-\mathrm{CH}=\mathrm{CH}-\mathrm{C}_{6} \mathrm{H}_{5}$

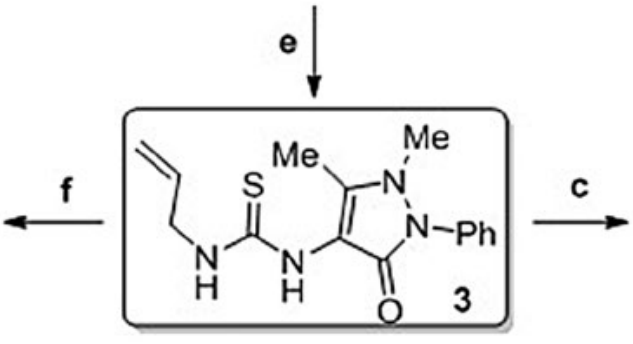

$$
\text { (2) }
$$

17-19

Scheme 1. Synthesis of thiazolidin-4-ones with pyrazolin-5-one moiety in molecules (2-19). Reagents and conditions: (a) 1 (10 mmol), $\mathrm{NH}_{4} \mathrm{SCN}(10 \mathrm{mmol}), \mathrm{HCl}$ (conc.) $(10 \mathrm{mmol}), \mathrm{C}_{6} \mathrm{H}_{5} \mathrm{COCl}(10 \mathrm{mmol})$, acetone, $30 \mathrm{~min}$, heating; (b) $10 \% \mathrm{NaOH}$ (aq.), reflux, 1h, $61 \%$; (c) 2 or 3 (10 mmol), N-arylmaleimides (10 mmol), EtOH (20 mL), reflux, $2 \mathrm{~h}$, 57-89 \%; (d) 2 (10 mmol), $\mathrm{ClCH}_{2} \mathrm{COOH}(10 \mathrm{mmol}), \mathrm{R}$ '-CHO (10 mmol), AcONa (20 mmol), AcOH (10 mL), $3 \mathrm{~h}$, reflux, 51-64 \%; (e) 1 (10 mmol), allyl isothiocyanate (12 mmol), i-PrOH, $2 \mathrm{~h}$, reflux, $65 \%$; (f) 3 (10 mmol), maleic anhydride (10 mmol), EtOH $(20 \mathrm{~mL})$, reflux, $2 \mathrm{~h}, 74 \%$.

agents among such type of pyrazolin-5-one/ thiazolidin-4-one hybrids.

\section{Anti-inflammatory (anti-exudative) activity}

Fourteen novel synthesized pyrazolin-5-one/ thiazolidin-4-one hybrids have been studied for their anti-inflammatory activity in vivo on carrageenin-induced paw oedema in rats (Table 2). All tested derivatives possess antiexudative activity at different level. Five derivatives (34.5\% from total amount) 9, 10, 15, 16, 18 have demonstrated the effect, which was $\geq 50 \%$ compared to reference-drug (Diclofenac sodium) one. The derivatives 9 and $\mathbf{1 5}$ were found as the most active in the 
<smiles></smiles>

Amine rotameric forms
Fig. 2. Possible tautomeric/rotameric forms for compounds 4-15. experiment with the inhibition values of $48.3 \%$ and $50.6 \%$ respectively compared to the untreated (carrageenin) group. Their activity levels were almost equal to Diclofenac sodium effect.

The SAR studies revealed that the activity level depends on the nature of C-5 as well as $\mathrm{N}-3$ attached substituents in thiazolidin-4-one ring. The C-5-ylidene derivatives (7-15) resulted in a higher activity level than [the] C-5N-phenylacetamide ones (4-6) in series of [the] N-3-unsubstituted compounds (4-15). The derivative 15 with [the] C-5-propenylidene fragment was found to be the most active among all tested compounds (50.6\% inhibition, activity relative Diclofenac sodium $97.7 \%)$. The derivative 9 with the C-5-( $p$ chloro)-benzylidene substituent demonstrated a lower level of activity and its inhibition value was $48.3 \%$ (93.2\% compared] to the reference drug activity). The introduction of both acetic acid residue in $\mathrm{C}-5$ position and allyl group in position N-3 (compounds 16-19) did not provide for significant improvement of anti-exudative properties (Table 2). However noteworthy, the presence of carboxylic group in structure (16) is eventually an advantage feature and could be used for the properties optimization through the synthesis of watersoluble organic/inorganic salts and thus an increase in the bioavailability/activity. The most active derivatives 9, 15, 18 were evaluated for their impact on the liver enzyme function and ulcerogenic activity (Table 3 ).

Thus, the compounds $\mathbf{9}, \mathbf{1 5}, \mathbf{1 8}$ do not lead to the appearance of negative changes in the key liver enzymes function as well as do not induce ulcerogenic action. 
Table 2. In vivo anti-inflammatory activity of compounds 4-11, 13, 15-19 on carrageenin-induced paw oedema in white rats (intraperitoneally use; doses: carrageenin $1 \%, 0.1 \mathrm{~mL}$; Diclofenac sodium $8 \mathrm{mg} / \mathrm{kg}$, tested compounds $-50 \mathrm{mg} / \mathrm{kg} ; M \pm \mathrm{m} ; \mathrm{n}=6$ in each group)

\begin{tabular}{l|c|c|c}
\hline $\begin{array}{c}\text { Compounds / Reference drug, } \\
\text { Doses }\end{array}$ & $\begin{array}{c}\text { Rat hind limb volume increase, } \\
4 \text { hours, \% }\end{array}$ & Inflammation inhibition, \% & $\begin{array}{c}\text { Activity relative to Diclofenac } \\
\text { sodium, \% }\end{array}$ \\
\hline Carrageenin & $127.9 \pm 6.3$ & - & - \\
\hline Diclofenac sodium & $61,6 \pm 3.8$ & 51.8 & - \\
\hline $\mathbf{4}$ & $109.6 \pm 7.7$ & 14.3 & 27.6 \\
\hline $\mathbf{5}$ & $96.2 \pm 8.1$ & 24.8 & 47.8 \\
\hline $\mathbf{6}$ & $104.1 \pm 9.3$ & 18.6 & 35.9 \\
\hline $\mathbf{7}$ & $111.8 \pm 10.2$ & 12.6 & 24.3 \\
\hline $\mathbf{8}$ & $99.1 \pm 7.4$ & 22.5 & 43.3 \\
\hline $\mathbf{9}$ & $66.1 \pm 4.3$ & 48.3 & 93.2 \\
\hline $\mathbf{1 0}$ & $94.6 \pm 8.0$ & 26.0 & 50.2 \\
\hline $\mathbf{1 1}$ & $98.1 \pm 6.9$ & 23.3 & 44.9 \\
\hline $\mathbf{1 3}$ & $103.1 \pm 9.9$ & 19.4 & 37.5 \\
\hline $\mathbf{1 6}$ & $63.2 \pm 4.6$ & 50.6 & 97.7 \\
\hline $\mathbf{1 7}$ & $89.9 \pm 8.6$ & 29.7 & 57.3 \\
\hline $\mathbf{1 8}$ & $105.5 \pm 10.0$ & 17.5 & 33.8 \\
\hline $\mathbf{1 9}$ & $87.7 \pm 6.3$ & 31.4 & 60.6 \\
\hline
\end{tabular}

Summerizing our studies on the search for potential anti-inflammatory agents among antipyryl-4 based thiazolidin-4-ones we have observed the next SAR (Fig. 3): a) the hybrids with antipyryl-4 fragment linked in N-3 position of thiazolidin-4-one nucleus are optimal and possess anti-exudative activity higher than the relevant reference drugs; b) cinnamic aldehydes and $p$-chloro-benzaldehyde moieties in C-5 position of thiazolidin-4-one are pivotal and optimal for their activity; c) 2-thioxoderivatives of 3-(antipyryl-4)-thiazolidin4-ones demonstrate a higher activity level compare[d] to 2-oxoanalogs; d) replacement of the aromatic aldehyde fragments at C-5 position by acetic acid or R-phenylacetamides residues provoke attenuation of the anti-exudative effect; e) introduction of the second pyrazolone fragment linked via imine/amine linker as well as it replacement from position 3 to 2 in the position 2 of thiazolidin-4-one does not enhance the anti-exudative effect; f) introduction of allyl group in N-3 position does not cause a positive impact on the effect.

The mechanism of anti-exudative action for 5-substituted antipyryl-4 based thiazolidin4-ones (Fig. 3) seems very attractive for study due to the presence of set potential pharmacophore fragments in their molecules. It is known that pyrazolones act by the inhibition of both isoforms of cyclooxygenase (COX-1, COX-2, and $\mathrm{COX}-3$ ) enzymes involved in the prostaglandin (PG) synthesis $[4,36]$. The inhibition of 5-lipoxygenase (5-LOX), COX-2 and phospholipases A2 (PLA2s) has been reported for 5-ene-thiazolid-4-one scaffold [37]. Nowadays 
Table 3. Studies of key liver enzymes function and ulcerogenic action in treatment with compounds 9, 15, 18 and Diclofenac sodium under carrageenin-induced paw oedema in white rats (intraperitoneally use; doses: carrageenin $1 \%, 0.1 \mathrm{~mL}$; Diclofenac sodium $-8 \mathrm{mg} / \mathrm{kg}$, tested compounds $-50 \mathrm{mg} / \mathrm{kg} ; \mathrm{M} \pm \mathrm{m}$; $\mathrm{n}=6$ in each group)

\begin{tabular}{l|c|c|c|c|c|c}
\hline Compounds/ Parameters & ALT, U/1 & AST,, $\mathrm{U} / 1$ & ALPc, IU/1 & $\gamma$-GGTd, IU/1 & $\begin{array}{c}\text { Animals with } \\
\text { ulcers, } \mathrm{n} \text { ' }\end{array}$ & $\begin{array}{c}\text { Ulcer degree, } \\
\text { points }\end{array}$ \\
\hline Intact animals* & $61.1-84.5$ & $139.3-194.6$ & $180.2-281.9$ & $1.8-4.8$ & 0 & $0 \pm 0.00$ \\
\hline Diclofenac sodium & $79.7 \pm 6.2$ & $184.1 \pm 19.7$ & $233.0 \pm 23.9$ & $3.0 \pm 0.5$ & 2 & $1.0 \pm 0.1$ \\
\hline $\mathbf{9}$ & $67.5 \pm 5.9$ & $149.9 \pm 15.2$ & $206.7 \pm 20.9$ & $2.6 \pm 0.6$ & 0 & $0 \pm 0.00$ \\
\hline $\mathbf{1 5}$ & $74.0 \pm 7.1$ & $168.3 \pm 20.4$ & $212.4 \pm 22.7$ & $2.1 \pm 0.4$ & 0 & $0 \pm 0.00$ \\
\hline $\mathbf{1 8}$ & $75.5 \pm 8.3$ & $152.7 \pm 23.6$ & $221.3 \pm 25.8$ & $2.9 \pm 0.6$ & 0 & $0 \pm 0.00$ \\
\hline
\end{tabular}

* — the data for intact male albino rats groups from LNMU vivarium were used; ${ }^{\mathrm{a}}-1 \mathrm{U}=0.0165 \mu \mathrm{kat} / \mathrm{L}$; ${ }^{\mathrm{b}}-$ $1 \mathrm{U}=0.0167 \mu \mathrm{kat} / \mathrm{L} ;{ }^{\mathrm{c}}-1 \mathrm{IU}=0.1667 \mu \mathrm{kat} / \mathrm{L} ;{ }^{\mathrm{d}}-1 \mathrm{U}=0.1667 \mu \mathrm{kat} / \mathrm{L}$

the modulation of nuclear factor kappa-lightchain-enhancer of the activated B cells (NF$\mathrm{kB})$ signaling pathway is considered as the potential target for 5-ene-thiazolid-4-ones and as a promising molecular mechanism for antiinflammatory effect [38]. Also, it is also important and worth to note that the presence of cinnamic aldehydes residues resulting in the best activity level for $\mathbf{1 5}$ (as well as for previously reported analogues [15-18]) is a com- mon structure feature with known pharmacological agent Epalrestat (ONO-2235), which was originally developed as the aldose reductase (ALR) inhibitor and used for the treatment of diabetic neuropathy. According to modern insights the inhibition of aldose reductase is one of the prospective strategies for design of potential anti-inflammatory agents [39]. Thus, for the all above-mentioned reasons the multitarget anti-inflammatory action might be ex-

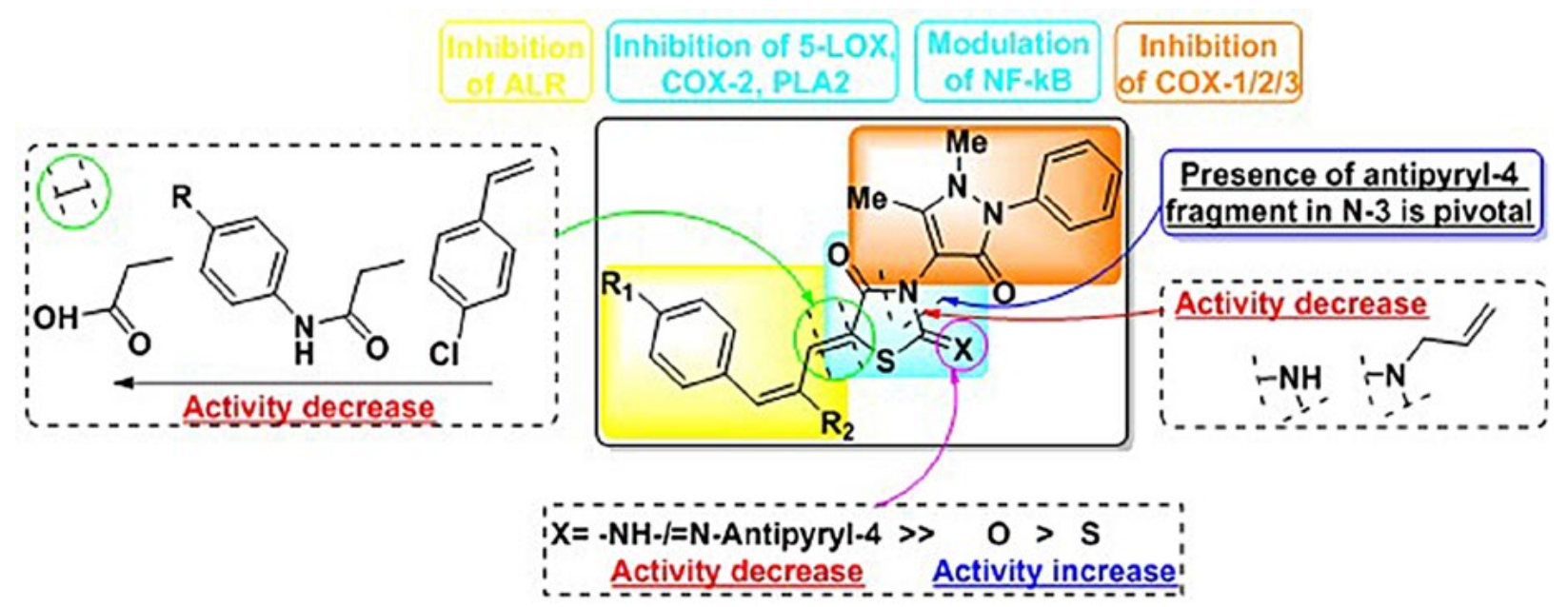

Fig. 3. Possible potential anti-inflammatory pharmacophores and structure - anti-inflammatory activity relationships for antipyryl-4 based thiazolidin-4-ones. 
pected for this class of molecular hybrids and, undoubtedly, more comprehensive additional research is required.

\section{Conclusions}

In this paper the synthetic approaches to series of novel 2-imine/amine-(antipyryl-4)-thiazolidin-4-ones were proposed. The structure and tautomerism of synthesized compounds were confirmed and studied using LC-MS and ${ }^{1} \mathrm{H}$ NMR, IR spectra. The selected compounds were evaluated for their anticancer and antiinflammatory activities. The lead-compounds were identified, which were equal to the reference drug Diclofenac sodium by the anti-inflammatory activity but had neither negative impact on the key liver enzymes function nor ulcerogenic action. The SARs were formed and possible mechanisms of action were discussed. The obtained results are promising for the future design and synthesis of new pyrazolin-5-on/thiazolidin-4-one hybrids as the potential molecules with promising pharmacological properties.

\section{Funding}

This work was partially supported by COST Action NutRedOx-CA161112 "Personalized Nutrition in ageing society: redox control of major aged-related diseases" (for Holota S.) and Ministry of Healthcare of Ukraine (project 0121U100690).

\section{REFERENCES}

1. Brune $K$. The early history of non-opioid analgesics. Acute Pain. 1997; 1(1):33-40.

2. Zhao Z, Dai X, Li C, Wang X, Tian J, Feng Y, Xie J, Ma C, Nie Z, Fan P, Qian M, He X, Wu S, Zhang Y, $Z$ Zheng $X$. Pyrazolone structural motif in medicinal chemistry: Retrospect and prospect. Eur J Med Chem. 2020;186:111893.

3. Sahoo J, Sahoo CR, Nandini Sarangi PK, Prusty SK, Padhy RN, Paidesetty SK. Molecules with versatile biological activities bearing antipyrinyl nucleus as pharmacophore. Eur J Med Chem. 2020;186:111911.

4. Tripathy R, McHugh RJ, Ghose AK, Ott GR, Angeles TS, Albom MS, Huang Z, Aimone LD, Cheng M, Dorsey $B D$. Pyrazolone-based anaplastic lymphoma kinase (ALK) inhibitors: control of selectivity by a benzyloxy group. Bioorg Med Chem Lett. 2011; 21(24):7261-4.

5. Gu W, Dai Y, Qiang H, Shi W, Liao C, Zhao F, Huang $W$, Qian H. Discovery of novel 2-substituted4-(2-fluorophenoxy) pyridine derivatives possessing pyrazolone and triazole moieties as dual c-Met/ VEGFR-2 receptor tyrosine kinase inhibitors. Bioorg Chem. 2017;72:116-122.

6. Norman $M H$, Liu L, Lee $M, X i N$, Fellows I, D'Angelo ND, Dominguez $C$, Rex K, Bellon SF, Kim TS, Dussault I. Structure-based design of novel class II c-Met inhibitors: 1. Identification of pyrazolone-based derivatives. J Med Chem. 2012;55(5): 1858-67.

7. Zhou S, Ren J, Liu M, Ren L, Liu Y, Gong P. Design, synthesis and pharmacological evaluation of 6,7-disubstituted-4-phenoxyquinoline derivatives as potential antitumor agents. Bioorg Chem. 2014;57:30-42.

8. Mahajan SS, Scian M, Sripathy S, Posakony J, Lao U, Loe TK, Leko V, Thalhofer A, Schuler AD, Bedalov A, Simon JA. Development of pyrazolone and isoxazol-5-one cambinol analogues as sirtuin inhibitors. J Med Chem. 2014;57(8):3283-94.

9. Marković V, Erić S, Stanojković T, Gligorijević N, Aranđelović $S$, Todorović $N$, Trifunović $S$, Manojlović N, Jelić R, Joksović MD. Antiproliferative activity and QSAR studies of a series of new 4-aminomethylidene derivatives of some pyrazol-5-ones. Bioorg Med Chem Lett. 2011; 21(15):4416-21.

10. Zhang $M$, Xie ZF, Zhang RT, Chen DK, Gu M, Cui SC, Zhang YM, Zhang XW, Yu YY, Li J, Nan FJ, $L i J Y$. Novel substituted pyrazolone derivatives as 
AMP-activated protein kinase activators to inhibit lipid synthesis and reduce lipid accumulation in ob/ ob mice. Acta Pharmacol Sin. 2018;39(10):16221632.

11. Eldebss TMA, Farag AM, Abdalla MM, Khedr AA. Synthesis of some new pyrazolone-based heterocycles con-taining sulphone moiety acting as $\alpha$-glucosidase and $\alpha$-amylase inhibitors. J Heterocycl Chem. 2019; 56(3):765-80.

12. Kirsch P, Hartman AM, Hirsch AKH, Empting M. Concepts and Core Principles of Fragment-Based Drug Design. Molecules. 2019;24(23):4309.

13. Rao PP, Kabir SN, Mohamed T. Nonsteroidal AntiInflammatory Drugs (NSAIDs): Progress in Small Molecule Drug Development. Pharmaceuticals (Basel). 2010;3(5):1530-1549.

14. Zimenkovsky B, Lesyk R, Vladzimirska O, Nektegayev I, Golota S, Chorniy I. The structure - antiinflammatory activity relationship among thiazolidones: Conclusion from scientific programme. J Pharm Pharmacol. 1999; 51:264.

15. Lesyk R, Vladzimirska O, Zimenkovsky B, Golota S, Nektgayev I, Cherpak O, Leb'yak M, Kozak $O$. Synthesis and antiinflammatory activity of novel 3-(2,3-dimethyl-1-phenyl-4-pyrazolon5-yl)-4-thiazolidones. Boll Chim Farm. 2002; 141(3): 197-201.

16. Golota SM, Danylyuk KE, Yushchenko TI, Voloshchuk NI, Bilyk OV, Lesyk RB. The synthesis of 4-thiazolidinone derivatives using 2-(4-R2-formylphenoxy)-N-(R'-phenyl)acetamides and their anti-inflammatory activity. J Org Pharm Chem. 2015; 3(51):15-20.

17. Holota SM, Derkach HO, Demchuk IL, Vynnytska RB, Antoniv OI, Furdychko LO, Slyvka NYu, Nektegayev IO, Lesyk RB. Synthesis and in vivo evaluation of pyrazoline-thiazolidin4-one hybrid Les-5581 as a potential non-steroidal anti-inflammatory agent. Biopolym Cell. 2019; 35(6):437-47.

18. Cherkas A, Golota S. An intermittent exhaustion of the pool of glycogen in the human organism as a simple universal health promoting mechanism. Med Hypotheses. 2014;82(3):387-9.
19. Cherkas A, Eckl P, Gueraud F, Abrahamovych O, Serhiyenko V, Yatskevych O, Pliatsko M, Golota S. Helicobacter pylori in sedentary men is linked to higher heart rate, sympathetic activity, and insulin resistance but not inflammation or oxidative stress. Croat Med J. 2016;57(2):141-9.

20. Cherkas A, Golota S, Guéraud F, Abrahamovych O, Pichler C, Nersesyan A, Krupak V, Bugiichyk V, Yatskevych O, Pliatsko M, Eckl P, Knasmüller S. A Helicobacter pylori-associated insulin resistance in asymptomatic sedentary young men does not correlate with inflammatory markers and urine levels of 8-iso-PGF2- $\alpha$ or 1,4-dihydroxynonane mercapturic acid. Arch Physiol Biochem. 2018;124(3): 275-285.

21. Cherkas A, Abrahamovych O, Golota S, Nersesyan A, Pichler C, Serhiyenko V, Knasmüller $S$, Zarkovic N, Eckl P. The correlations of glycated hemoglobin and carbohydrate metabolism parameters with heart rate variability in apparently healthy sedentary young male subjects. Redox Biol. 2015; 5:301-307.

22. Cherkas A, Holota S, Mdzinarashvili T, Gabbianelli $R$, Zarkovic $N$. Glucose as a Major Antioxidant: When, What for and Why It Fails? Antioxidants (Basel). 2020;9(2):140.

23. Lal N, Kumar J, Erdahl WE, Pfeiffer DR, Gadd ME, Graff G, Yanni JM. Differential effects of non-steroidal anti-inflammatory drugs on mitochondrial dysfunction during oxidative stress. Arch Biochem Biophys. 2009;490(1):1-8.

24. Hussain T, Tan B, Yin Y, Blachier F, Tossou MC, Rahu N. Oxidative Stress and Inflammation: What Polyphenols Can Do for Us? Oxid Med Cell Longev. 2016;2016:7432797.

25. Schadich E, Kryshchyshyn-Dylevych A, Holota S, Polishchuk P, Džubak P, Gurska S, Hajduch M, Lesyk $R$. Assessing different thiazolidine and thiazole based compounds as antileishmanial scaffolds. Bioorg Med Chem Lett. 2020;30(23):127616.

26. Holota S, Shylych Ya, Derkach H, Karpenko O, Gzella A, Lesyk R. Synthesis of 4-(2H-[1,2,4]-Triazol-5-ylsulfanyl)-1,2-dihydropyrazol-3-one via Ring-Switching Hydrazinolysis of 5-Ethoxymethyli- 
denethiazolo[3,2-b][1,2,4]triazol-6-one. Molbank. 2018; 2018(4):M1022.

27. Holota SM, Derkach GO, Zasidko VV, Trokhymchuk VV, Furdychko LO, Demchuk IL, Semenciv GM, Soronovych II, Kutsyk RV, Lesyk RB. Features of antimicrobial activity of some 5-aminomethylene-2-thioxo-4-thiazolidinones. Biopolym Cell. 2019;35(5):371-80.

28. Monks A, Scudiero D, Skehan P, Shoemaker R, Paull K, Vistica D, Hose C, Langley J, Cronise P, Vaigro-Wolff $A$, et al. Feasibility of a high-flux anticancer drug screen using a diverse panel of cultured human tumor cell lines. $J$ Natl Cancer Inst. 1991;83(11):757-66.

29. Boyd MR, Paull KD. Some practical considerations and applications of the national cancer institute in vitro anti-cancer drug discovery screen. Drug Dev Res. 1995;34(2):91-109.

30. Winter CA, Risley EA, Nuss GW. Carrageenin-induced edema in hind paw of the rat as an assay for antiiflammatory drugs. Proc Soc Exp Biol Med. 1962;111:544-7.

31. Stefanov $O V$. [Doklinichni doslidzhennya likarskyh zasobiv: Metodychni rekomendatsii]. Kyiv: 2001; $528 \mathrm{p}$.

32. Golota S, Sydorenko I, Surma R, Karpenko O, Gzella A, Lesyk R. Facile one-pot synthesis of 5-aryl/ heterylidene-2-(2-hydroxyethyl- and 3-hydroxypropylamino)-thiazol-4-ones via catalytic aminolysis. Synth Comm. 2017; 47(11):1071-6.

33. Wong RSY. Role of Nonsteroidal Anti-Inflammatory Drugs (NSAIDs) in Cancer Prevention and Cancer Promotion. Adv Pharmacol Sci. 2019;2019:3418975.

34. Zappavigna S, Cossu AM, Grimaldi A, Bocchetti $M$, Ferraro GA, Nicoletti GF, Filosa R, Caraglia M. Anti-Inflammatory Drugs as Anticancer Agents. Int J Mol Sci. 2020;21(7):2605.

35. Elattar KM, Fadda AA. Chemistry of antipyrine. Synth Comm. 2016;46(19): 1567-94.

36. Liaras K, Fesatidou M, Geronikaki A. Thiazoles and Thiazolidinones as COX/LOX Inhibitors. Molecules. 2018;23(3):685.

37. Panico A, Maccari R, Cardile V, Avondo S, Crascì L, Ottanà R. Evaluation of the an-ti-inflammatory/ chondroprotective activity of aldose reductase in- hibitors in human chondrocyte cultures. MedChemComm. 2015;6(5):823-30.

38. Chatzopoulou M, Pegklidou K, Papastavrou N, Demopoulos VJ. Development of aldose reductase inhibitors for the treatment of inflammatory disorders. Expert Opin Drug Discov. 2013;8(11): 1365-80.

\section{Синтез, характеристика та біологічна оцінка нових піразолін-5-он-заміщених тіазолідин- 4-онів}

С. М. Голота, I. О. Нєктєгаєв, I. I. Соронович, I. I. Чубучна, М. А. Колішецька, С П. Сисак, М. С. Регеда, Р. Б. Лесик

Мета. Синтез, визначення структури, дослідження in vivo протизапальної (антиексудативної) та ульцерогенної активності, оцінка впливу на функцію печінки нових піразолін-5-он заміщених тіазолідин-4-онів. Методи. Традиційний органічний синтез: мультикомпонентні реакції (МКР), реакції [2+3]-циклоприєднання. Спектральні методи: ІЧ, РХ-МС, ${ }^{1} \mathrm{H}$ ЯМР. Біологічні методи: дослідження протиракової активності (протокол NCI (NIH, CША) 3 лінії ракових клітин); карагенін-індукована модель запального набряку лапи білих щурів, біохімічні лабораторні дослідження (визначення рівня АЛТ, АСТ, ЛФ, $\gamma$-ГГТ); оцінка ульцерогенної дії. Результати. Серію нових C-5 i N-3 заміщених 2-[(1,5-диметил-3-оксо-2-феніл2,3-дигідро- $1 H$-піразол-4-іл]аміно/іміно)тіазолід-ин4-онів, як потенційних біологічно активних сполук, було синтезовано з використанням МКР та реакцій $[2+3]$-циклоприєднання. За результати скринінгу антиексудативної активності встановлено, що тестовані похідні виявляють протизапальний ефект. Визначені залежності “структура-протизапальна активність” для антипірин-заміщених тіазолідин-4-онів та обговорені можливі механізми дії. Висновки. Отримані і представлені в роботі результати свідчать про те, що дизайн та синтез нових піразолін-5-он/тіазолідин-4онових гібридів $\epsilon$ перспективним напрямком для пошуку нових молекул/агентів 3 потенційними фармакологічними властивостями.

К л юч о в і с л о в а: антипірин, піразолін-5-он, тіазолідин-4-он, гібридні молекули, багатокомпонент- 
ні реакції, таутомери/ротамери, протиракова/протизапальна активність.

\section{Синтез, характеристика и биологическая оценка новых пиразолина-5-он-замещенных тиазолидин-4-онов}

С. Н. Голота, И. А. Нектегаев, И. И. Соронович, И. И. Чубучна, М. А. Колишецка, С П. Сысак, М. С. Регеда, Р. Б. Лесык

Цель. Синтез, определение структуры, исследования in vivo противовоспалительной (антиэкссудативной) и ульцерогенной активности, оценка влияния на функцию печени новых пиразолина-5-он замещенных тиазолидин-4-онов. Методы. Традиционный органический синтез: мультикомпонентные реакции (МКР), реакции [2+3]-циклоприсоединения. Спектральные методы: ИК, ЖХ-МС, ${ }^{1} \mathrm{H}$ ЯМР. Биологические методы: исследование противораковой активности (протокол NCI (NIH, CША) 3 линии раковых клеток); карагенин-индуцированная модель воспалительного отека лапы белых крыс; биохимические лабораторные исследования (определение уровня АЛТ, АСТ, ЩФ, $\gamma$-ГГТ) оценка ульцерогенного действия. Результаты.
Серию новых C-5 и N-3 замещенных 2-[(1,5-диметил3-оксо-2-фенил-2,3-дигидро-1 $H$-пиразол-4-ил]амино/ имино)тиазолид-ин- 4-онов, как потенциальных биологически активных соединений, было синтезировано с использованием МКР и реакций [2+3]-циклоприсоединения. По результатам скрининга антиэкссудативного активности установлено, что тестируемые производные проявляют противовоспалительный эффект. Определены зависимости «структура-противовоспалительная активность» для антипирин-замещенных тиазолидин-4-онов и обсуждены возможные механизмы действия. Выводы. Полученные и представленные в работе результаты свидетельствуют о том, что дизайн и синтез новых пиразолин-5-он/тиазолидин-4-оновых гибридов является перспективным направлением для поиска новых молекул/агентов с потенциальными фармакологическими свойствами.

Кл юч е в ы е сл ов а: антипирин, пиразолин-5-он, тиазолидин-4-он, гибридные молекулы, многокомпонентные реакции, таутомеры/ротамеры, противораковая/противовоспалительная активность.

Received 15.10.2020 